\title{
鹖pubvet
}

https://doi.org/10.22256/pubvet.v12n5a92.1-12

\section{Selênio para caprinos e ovinos: Revisão}

\section{Juliete de Lima Gonçalves ${ }^{\ominus}$ 1* $^{*}$ Fábio Carreiro Chaves de Melo ${ }^{\ominus 2}$, Rafael Teixeira de Sousa ${ }^{\ominus}$, Sueli Freitas dos Santos $^{\ominus}$, Antonio Marcos Ferreira Fernandes ${ }^{\ominus}$}

${ }^{1}$ Doutoranda em Zootecnia, Universidade Federal da Paraíba, Areia, Paraíba. E-mail: julietegoncalves@gmail.com . ${ }^{2}$ Mestre em Zootecnia, Universidade Estadual Vale do Acaraú, Sobral, Ceará. E-mail: fabbio.mello@hotmail.com .

${ }^{3}$ Doutor em Nutrição e Produção Animal, Faculdade de Medicina Veterinária e Zootecnia, Universidade de São Paulo, Pirassununga, São Paulo. E-mail: rafaelvnp@usp.br.

${ }^{3}$ Doutora em Zootecnia, Universidade Federal do Ceará, Fortaleza, Ceará. E-mail: sfsantoszootecnia@gmail.com .

${ }^{5}$ Mestre em Zootecnia, Universidade Estadual Vale do Acaraú, Sobral, Ceará. E-mail: mascosff90@gmail.com .

*Autor para correspondência.

RESUMO. A nutrição demanda o maior custo de produção de caprinos e ovinos e devido a este motivo, maiores lucratividades podem ser conseguidas nos detalhes. Onde cada nutriente tem sua importância, sendo que alguns deles tem destaque diferenciado, é o caso do se. Dentro da fisiologia animal, o se é multifuncional, sendo essencial para o funcionamento normal de diversas rotas metabólicas. Como antioxidante o se, a nível celular, promove um feedback importante entre a atividade metabólica de alguns órgãos e a regulação do funcionamento celular. Além de contribuir para a homeostase nutricional e melhor desempenho dos animais. Ademais, sua ação antioxidante otimiza e protege a vitamina $\mathrm{E}$, aumenta a atividade das células de defesa, reduz a severidade das infecções secundárias principalmente na defesa da glândula mamária. Juntamente com cobre, zinco e vitamina E, compõem o sistema imune dos animais. Em dietas deficientes, a suplementação de se tem mostrado reduzir a retenção de placenta. Em deficiência pode levar os animais ao anestro, diminuir a fertilidade do óvulo, diminuindo a taxa de concepção e também a produção de carne, leite e lã. Nesse sentido, esta revisão bibliográfica tem como objetivo abordar alguns aspectos relacionados ao se sobre o desempenho reprodutivo e produtivo de caprinos e ovino e também a sua relação com a sanidade dessas espécies. E de acordo com levantamento bibliográfico apresentado nessa revisão, conclui-se que o se possui amplas funcionalidades nas áreas de nutrição, sanidade e reprodução, aprimorando os sistemas de produção de caprinos e ovinos, uma vez que aumenta o ganho de peso, a produção de leite e lã dos animais. Reduz o risco de doenças como a mastite e contaminações por verminose, além de aumentar a taxa de fertilidade, e redução da retenção de placenta.

Palavras chave: imunidade, pequenos ruminantes, produtividade

\section{Selenium for goats and sheep: Review}

ABSTRACT. Nutrition demands the higher cost of production of goats and sheep and because of this reason, greater profitability can be achieved in the details. Where each nutrient has its importance, and some of them are highlighted differently, is the case of selenium. Within animal physiology, selenium is multifunctional and essential for the normal functioning of various metabolic pathways. As an antioxidant, selenium, at the cellular level, promotes important feedback between the metabolic activity of some organs and the regulation of cellular functioning. In addition to contributing to the nutritional homeostasis and better performance of the animals. In addition, its antioxidant action optimizes and protects vitamin $\mathrm{E}$, increase the activity of defense cells, reduces the severity 
of secondary infections mainly in the defense of the mammary gland. Together with copper, zinc and vitamin E, make up the immune system of animals. In deficient diets, selenium supplementation has been shown to reduce placental retention. In deficiency it can lead the animals to anestrus, decrease the fertility of the ovum, reducing the rate of conception and also the production of meat, milk and wool. In this sense, this bibliographic review aims to address some aspects related to selenium on the reproductive and productive performance of goats and sheep and also their relation with the sanity of these species. According to a literature review presented in this review, it is concluded that selenium has broad functionalities in the areas of nutrition, sanitation and reproduction, improving the production systems of goats and sheep, since it increases the weight gain, the production of milk and animal wool. Reduces the risk of diseases such as mastitis and vermin contamination, as well as increasing fertility rate, and reducing placental retention.

Keywords: immunity, small ruminants, productivity

\section{Selenio para caprinos y ovinos: Revisión}

RESUMEN. La nutrición demanda el mayor costo de producción de caprinos y ovinos y debido a éste motivo, mayores rentabilidades pueden lograrse en con detalles. Donde cada nutriente tiene su importancia, siendo que algunos de ellos tienen destaque diferenciado, es el caso del Selenio. Dentro de la fisiología animal, el selenio es multifuncional, siendo esencial para el funcionamiento normal de diversas rutas metabólicas. Como antioxidante el selenio, a nivel celular, promueve una retroalimentación importante entre la actividad metabólica de algunos órganos y la regulación del funcionamiento celular. Además de contribuir a la homeostasis nutricional y mejor desempeño de los animales. Además, su acción antioxidante optimiza y protege la vitamina E, aumenta la actividad de las células de defensa, reduce la severidad de las infecciones secundarias principalmente en la defensa de la glándula mamaria. Junto con cobre, zinc y vitamina E, componen el sistema inmune de los animales. En las dietas deficientes, la suplementación de selenio ha demostrado reducir la retención de la placenta. En deficiencia puede llevar a los animales al anestro, disminuir la fertilidad del óvulo, disminuyendo la tasa de concepción y también la producción de carne, leche y lana. En este sentido, esta revisión bibliográfica tiene como objetivo abordar algunos aspectos relacionados al selenio sobre el desempeño reproductivo y productivo de caprinos y ovino y también su relación con la sanidad de esas especies. Y de acuerdo con el levantamiento bibliográfico presentado en esta revisión, se concluye que el selenio posee amplias funcionalidades en las áreas de nutrición, sanidad y reproducción, perfeccionando los sistemas de producción de caprinos y ovinos, una vez que aumenta la ganancia de peso, la producción de ganado leche y lana de los animales. Reduce el riesgo de enfermedades como la mastitis y las contaminaciones por verminosas, además de aumentar la tasa de fertilidad, y la reducción de la retención de la placenta.

Palabras clave: inmunidad, pequeños rumiantes, productividad

\section{Introdução}

Além exigências nutricionais referentes à proteína e energia, caprinos e ovinos possuem uma demanda por minerais e algumas vitaminas. E dentre os minerais o selênio, assume posição de destaque na nutrição de caprinos e ovinos, sendo necessário para o crescimento e a fertilidade e vários outros mecanismos fisiológicos ( $\underline{\text { Schrauzer }}$ \& Surai 2009).

De acordo com Gresakova et al. (2013) o Se possui funções importantes quando associados às proteínas, formando as seleno-proteínas, das quais a glutationa peroxidase é a mais importante. A glutationa peroxidase é uma enzima que trabalha na desintoxicação do peróxido de hidrogênio e lipídeos hidroperóxidos (Ramírez-Bribiesca et al. 2005). O selênio favorece a síntese de hormônios derivados do ácido araquidônico, do metabolismo de compostos estranhos ao organismo e no transporte de alguns aminoácidos nos rins (Brown \& Arthur 2001). Assim o selênio desempenha três funções no organismo que são: defesa antioxidante, metabolismo do hormônio da tireoide e controle das reações celulares (Chauhan et al. 2014). 
Várias fontes de selênio estão sendo utilizadas na dieta de caprinos e ovinos com o intuito de aumentar sua concentração na carne e no leite (Mirjana et al. 2016). Além disso, a utilização do Se promove bons resultados na reprodução e sanidade dos animais. O selênio possui várias funções do organismo tais como: crescimento, reprodução, atividade imunológica, prevenção de doenças e manutenção da integridade das células e dos tecidos (Chauhan et al. 2014). E devido a esses fatores, há a necessidade de se elucidar alguns fatores de como o Se age, qual a sua biodisponibilidade, distribuição no organismo, absorção, buscando mensurar seus benefícios, já que a carne caprina e ovina e o leite são amplamente utilizados na alimentação humana.

\section{Concentração do se nos tecidos dos pequenos ruminantes}

$\mathrm{O}$ uso de fontes ricas em selênio na alimentação de caprinos e ovinos pode aumentar as concentrações deste mineral nos tecidos dos mesmos, servindo de mais uma fonte alimentar para os consumidores da carne e leite caprino. Juniper et al. (2009) trabalhando com altas doses de Se a base de leveduras (Saccharomyces cerevisiae) na alimentação de cordeiros observaram uma maior concentração de $\mathrm{Se}$ no sangue dos animais que foram suplementados $(815,2 \pm 19,1 \mathrm{mg} \mathrm{Se} / \mathrm{ml})$ quando comparados com o grupo não suplementado $(217,8 \pm 9,1 \mathrm{mg} \mathrm{Se} / \mathrm{ml})$. Os mesmos ressaltam que os valores encontrados nos tecidos dos animais que receberam dieta com $\mathrm{Se}$, foram de $26,16,8$ e 3 vezes maior no músculo esquelético, fígado, coração e tecido renal, respectivamente, nos cordeiros tratados em relação ao grupo controle. Davis et al. (2006) afirmaram que a concentração de selênio nas dietas de ovelhas gestantes influencia na concentração de selênio no plasma de cordeiros, indicando que há transferência placentária de selênio.

Rock et al. (2001) alimentando ovelhas gestantes com 0,3 ppm de selênio, com fontes de selenito de sódio para verificar as concentrações de selênio nos hormônios da tireoide, nos tecidos e no soros obtiveram maior concentração de selênio no sangue total, no soro, maior atividade da glutationa peroxidase e maiores concentrações de triiodotironina (T3) e tiroxina (T4), quando comparados com o grupo que recebeu menos que $0,02 \mathrm{ppm}$ de Se. Os mesmos autores verificaram que os cordeiros provenientes das ovelhas que receberam a suplementação de selênio, nas primeiras 12 horas obtiveram maiores concentrações de selênio no sangue e no fígado além da maior atividade da glutationa peroxidase e níveis mais elevados de T3. Cristaldi et al. (2005) utilizando selenito de sódio verificaram que a medida que aumentaram a concentração de Se na dieta de ovelhas, maiores eram as concentrações nos tecidos, lã e cascos, sendo o fígado com maiores concentrações, seguido dos rins.

\section{Utilização do selênio e sua importância no leite e na carne de caprinos e ovinos}

Pesquisas vêm sendo realizadas com o intuído de aumentar o tempo de durabilidade da carne ovina nas prateleiras. Segundo Costa et al. (2009) o estado em que se encontra a oxidação dos lipídeos da carne depende de alguns fatores como: a composição dos fosfolipídios, quantidade de ácidos graxos poli-insaturados, concentração de íons metálicos, oxigênio, sal e outros oxidantes, sendo estes determinantes para uma maior ou menor grau de oxidação. Os mesmos ressaltam que o uso da vitamina $\mathrm{E}$ pode reduzir os efeitos negativos causado pela oxidação lipídica que consequentemente afetarão o odor e o sabor da carne de cordeiros. No entanto, Lauzurica et al. (2005) enfatizam que a associação da vitamina $\mathrm{E}$ com o selênio desempenham função antioxidante protetora das membranas plasmáticas contra a ação tóxica dos peróxidos lipídicos.

O uso de selênio na alimentação dos animais pode proporcionar uma maior concentração deste na carne, leite e lã. Souza et al. (2009) confirmaram essa afirmação, preconizando que a inclusão de fontes orgânicas de selênio promovem maiores concentrações de selênio na carne de cordeiros. Vignola et al. (2009) trabalhando com a suplementação de diferentes fontes de selênio e diferentes níveis para verificar a estabilidade oxidativa da carne de cordeiros, verificaram que a suplementação com se aumentou o conteúdo de selênio no músculo, tendo um maior aumento quando os animais foram alimentados com selênio provenientes de leveduras (Saccharomyces cerevisiae). Taylor (2005) trabalhando com suplementação de selênio para cordeiros, com 0,2 $\mathrm{mg} / \mathrm{kg}$ e $2,9 \mathrm{mg} / \mathrm{kg}$ de selênio/dia com fontes orgânicas de selênio, observou maiores níveis de selênio no músculo dos animais suplementados com maiores concentrações. Mestchy (2000) destacou a necessidade diária de $0,1 \mathrm{mg}$ de $\mathrm{Se} / \mathrm{kg}$ de MS, na dieta de cabras gestantes. 
A concentração desse mineral não é somente encontrada na carne, mas também em outros produtos, como é o exemplo do leite. Ademais, a utilização do selênio orgânico, mostra que essa fonte de selênio aumenta a concentração do mesmo em até cinco vezes quando comparado com o selênio inorgânico, melhorando a qualidade do leite e prolongando o tempo de utilização, já que o se apresenta características antioxidantes (Chauhan et al. 2014).

Khaled \& Illek (1999) reportaram que a suplementação de selênio para cabras leiteiras em que foi fornecido $0,15 \mathrm{mg}$ de selênio orgânico $/ \mathrm{kg}$ de matéria seca (MS) constataram que os animais suplementados continham níveis mais elevados de selênio no plasma e no leite, quando comparados com o grupo não suplementado; porém este fator não interferiu na atividade da tireoide. Davis et al. (2006) comparando os efeitos de seis níveis de selênio $(0,2$ (controle), $4,8,12,16$ e $20 \mathrm{mg} / \mathrm{kg}$ ) no leite de ovelhas, verificaram que o selênio no leite de ovelha variou de 75-2228 $\mathrm{mg} / \mathrm{L}$ e aumentou de forma linear com o aumento do nível de selênio fornecido na dieta das ovelhas.

Em um estudo preliminar Morgante et al. (1999) encontraram uma menor percentagem de leucócitos neutrófilos e bactérias no leite de ovelhas quando suplementadas com selênio e vitamina E. Petrera et al. (2009) avaliaram a influência da fonte de selênio na dieta de cabras leiteiras e sua influência na qualidade do leite, verificando que os animais que receberam $\mathrm{Se}$ levedura (Saccharomyces cerevisiae) apresentaram uma maior concentração de selênio no leite quando comparados com o grupo controle e o selenito de sódio, mostrando uma maior absorção e incorporação de selênio no leite das cabras com o tratamento de seleno-levedura (Saccharomyces cerevisiae).

\section{O uso do selênio na nutrição de pequenos ruminantes}

A nutrição tem forte influência no bom desempenho do animal, proporcionando melhores desempenhos produtivos e reprodutivos, caso as exigências dos animais sejam atendidas (McDowell \& Hernandez-Urdaneta 1975). Tendo a nutrição importante papel no sistema imunológico do animal, sendo que a deficiência de alguns elementos essenciais pode levar a consequências negativas no sistema de defesa. Muitas vezes se fala apenas em deficiência de proteína e energia como um entrave para a produção de caprinos e ovinos. No entanto, a deficiência de minerais pode elevar esse problema, já que, exerce uma forte influência sobre $\mathrm{o}$ aproveitamento destes nutrientes (McDowell \& Hernandez-Urdaneta 1975). Pastrana et al. (1991) ressaltam que as quantidades de selênio tanto nas plantas forrageiras quanto no solo são deficientes, necessitando assim fazer uma suplementação desse mineral. Existem duas fontes de selênio na dieta do animal, sendo as fontes orgânicas e as inorgânicas. $\mathrm{O}$ uso de suplementos minerais orgânicos vem sendo utilizados constantemente, isso por que o mesmo possui uma absorção de quase $100 \%$, alta estabilidade, alta disponibilidade biológica, menor toxicidade, ausência de interação com alguns fatores da dieta como gorduras e fibras que podem formar ligações indesejáveis com os metais (Chauhan et al. 2014).

Koenig et al. (1997) fizeram uma pesquisa com ovinos utilizando dietas com alto concentrado e dietas com altas concentrações de forragem, na qual concluíram que a disponibilidade de selênio foi maior para dietas ricas em concentrados. Isso faz pensar que de acordo com a dieta fornecida à retenção e absorção do selênio pode ser maior ou menor. Soder \& Holden (1999) observaram que isto pode acontecer em decorrência do teor de levedura (Saccharomyces cerevisiae) que está anexado ao selênio orgânico, o que faz com que aumente o consumo, além de criar um ambiente propício para o desenvolvimento de bactérias no rúmen, o que melhora a assimilação de proteínas e minerais. Pastrana et al. (1991) trabalhando com ovelhas suplementadas com $0,1 \mathrm{mg} / \mathrm{kg}$ de selenito de sódio, observaram que as ovelhas suplementadas antes e no início do acasalamento produziram $1.036 \mathrm{~kg}$ cordeiros contra $725 \mathrm{~kg}$ do grupo controle ao desmame.

Uma das fontes alimentares para os pequenos ruminantes são as pastagens, no entanto muitas vezes essas são deficientes em selênio, que é um mineral muito importante para estes animais, portanto precisam ser suplementados. Nesse sentido, Hall et al. (2009) comparou o a fertilização do pasto com uma fonte de selênio juntamente com a adubação nitrogenada e a suplementação comumente utilizando o selenito de sódio inorgânico como suplemento mineral e verificaram que as concentrações de selênio no sangue de ovelhas foram maiores naquelas que estavam pastejando no pasto fertilizado com selênio em comparação naqueles que estavam no pasto sem fertilização de selênio, mas recebendo suplementação mineral de selenito de sódio. 
A utilização do selênio pode trazer bons resultados também no desempenho dos animais, obtendo-se maiores ganhos de peso quando os animais são suplementados com esse mineral. Shi et al. (2011) estudaram os efeitos de fontes orgânicas e inorgânicas e de nano- selênio sobre o desempenho de crescimento, a concentração de selênio e seus efeitos antioxidantes em caprinos. $\mathrm{O}$ mesmo mostrou que a condição corporal e o ganho médio diários dos caprinos em crescimento foram maiores no grupo suplementado com selênio, mostrando que a suplementação com nano- selênio pode ser usado mais eficaz quando comparado com o selênio orgânico e inorgânico. No entanto, Cristaldi et al. (2005) avaliaram o nível máximo tolerável de selênio provenientes de formas inorgânicas, utilizando selenito de sódio para proporcionar $0,2,2,4,6,8$ e $10 \mathrm{ppm}$ de selênio na dieta, verificando que a condição corporal não teve influência pelas concentrações dietéticas de selênio e que concentrações de $\leq 10$ ppm de selênio na dieta como selenito não é toxico em animais quando alimentados durante um ano.

\section{Importância do selênio de pequenos ruminantes}

Estudos têm demonstrado uma melhoria da qualidade cinética dos espermatozoides com adição de substâncias que combatam as espécies reativas de oxigênio, no meio diluente sendo utilizadas diversas substâncias como: vitaminas E e selênio, que possivelmente atuam como antioxidantes combatendo os radicais livres (Bucak et al. 2007).

Os minerais são considerados nutrientes fundamentais por participarem de diversas funções do metabolismo animal, compondo estruturas de biomoléculas, interferindo no crescimento e na manutenção de tecidos, participando como cofatores enzimáticos, ativando ações hormonais. Estes nutrientes representam apenas cerca de 5\% do peso total do corpo, mesmo assim, tem grande influência na produção do animal, acarretando acréscimos ou decréscimos na produtividade do sistema (Filappi et al. 2005)

$\mathrm{O}$ selênio pode substituir o enxofre na maioria das substâncias quelatadas, incluindo os aminoácidos que contém enxofre (Van Soest 1994; Berchielli et al. 2011). Durante muitos anos o selênio foi considerado como sendo tóxico para os animais. Porém, na última década de 2003 a compreensão de sua importância na nutrição de animais aumentou significativamente. Provavelmente, nenhum dos minerais envolvidos em nutrição animal sofreu tantas mudanças de conceito, quanto a sua real importância na nutrição dos animais quanto o selênio (Schrauzer \& Surai 2009). Em todas as espécies animais atribui-se influência do selênio no desempenho reprodutivo tanto de fêmeas como de machos (Smith \& Akinbamijo 2000). Segundo Mistry et al. (2012) em fêmeas este mineral se concentra nos ovários e exerce funções metabólicas, como: antioxidante na formação dos ovócitos e na maturação dos folículos que promovem a ovulação, pela ação da enzima glutationa peroxidase, que é vital para a proteção da membrana lipídica dos ovócitos, para que não sofra perioxidação pelos radicais livres, que causam a ruptura da membrana e danos irreversíveis. Os mesmos ressaltam que o selênio possui ação direta no metabolismo hormonal da progesterona, pois é uma seleno-proteína que estimula a síntese de prostaglandina $\mathrm{E}$, que protege o corpo lúteo, produtor de progesterona.

Deve-se se dar atenção à suplementação para fêmeas gestantes, para que não tenham suas reservas corporais de selênio esgotadas, o que poderia prejudicar a sua cria, por não possuir nível adequado do elemento no leite, a qual nasceria com deficiência de se, podendo ser fatal. Outra função do selênio é sua participação na produção de hormônios da tireoide, pois este é componente da enzima iodotironina deiodinase tipo I, responsável pela conversão de $\mathrm{T} 4 \mathrm{em} \mathrm{T} 3$, que é a forma fisiologicamente ativa (Berchielli et al. 2011).

A glutationa-peroxidase contém quatro átomos de selênio e forma a segunda linha de defesa de proteção das membranas plasmáticas contra a ação tóxica dos peróxidos lipídicos, depois da vitamina E (Berchielli et al. 2011). Há remoção de peróxido de hidrogênio pela conversão de glutationa oxidada em glutationa reduzida. $\mathrm{O}$ selênio, micronutriente essencial presente nos tecidos do corpo, caracteriza-se por uma versátil capacidade de oxirredução, sendo tal característica fundamental para sua atuação no centro ativo da enzima glutationa-peroxidase, responsável pela eliminação de peróxidos (Qin et al. 2007). A deficiência de selênio causa acúmulo de peróxidos nas membranas celulares causando necrose, com posterior fibrose e calcificação, principalmente nos músculos esquelético e cardíaco. De acordo com o NRC (2001), estudos mostraram que a prevalência de retenção de placenta, metrite, ovários císticos e edema de úbere foi diminuída 
pela suplementação de selênio em ruminantes durante a gestação.

Os macros minerais (fósforo, cálcio, sódio e enxofre) e os micros minerais (selênio, zinco e cobre) beneficiam a reprodução de forma interligada, de forma direta ou indireta. Portanto, a deficiência de selênio provoca algum tipo de desordem reprodutiva em todas as espécies animais de animais de produção e todos os sexos (Smith \& Akinbamijo 2000). Kamada \& Hodate (1998) constataram que o baixo teor de progesterona plasmática, que reduziu a concepção, aumentou a mortalidade de embriões, de abortos, aumentou a retenção de placenta e causou distúrbios no ciclo estral. A compreensão sobre a importância do selênio em ruminantes aumentou, tendo sido evidenciado que o selênio tem a capacidade de estimular o sistema imunológico e, por consequência, destruir bactérias, além de ter ações antioxidantes celulares (Brown \& Arthur 2001). De acordo com Gabryszuk \& Klewiec (2002) dentre os micro minerais, acredita-se que o selênio atua especificamente na melhora da sobrevivência do embrião. Portanto, animais com deficiência de selênio podem ter suprimida a capacidade de defesa contra doenças infecciosas, que poderiam prejudicar a sobrevivência do embrião (Ashworth 1995). Munsi et al. (2007) verificaram melhora na mortalidade espermática progressiva e redução das anormalidades espermáticas de animais tratados com glutationa peroxidase, comparados aos não tratados. O selênio é considerado um antioxidante, tendo como função o co-fator da glutationa peroxidase, enzima responsável pelo sistema de regulação extra e intracelular da hidroperoxidase (Luberda 2005). Uma pesquisa realizada com 12 cabras leiteiras saudáveis, durante 10 semanas, em que o tratamento controle recebeu dieta com 0,045 mg de Sel-Plex (Selenometionina) $/ \mathrm{kg}$ de MS e, um segundo tratamento recebeu dieta suplementada com $0,15 \mathrm{mg}$ de Sel$\mathrm{Plex} / \mathrm{kg}$ de MS. Verificou-se que os animais suplementados continham teores mais elevados de selênio no plasma e no leite, mas que isto não afetou atividade da tireoide (Khaled \& Illek 1999). Smith \& Akinbamijo (2000) constataram que as cabras também são susceptíveis a deficiência de $\mathrm{Se}$, o qual funciona como um componente citosólico para formar o co-fator da glutationa peroxidase, o qual reduz os peróxidos, evitando o ataque às membranas celulares. A enzima glutationa peroxidase é vital para proteção da membrana lipídica dos oócitos e para a maturação dos folículos ovulatórios, para que a membrana não sofra peroxidação pelos radicais livres, que causam a ruptura da mesma e danos graves irreversíveis (Brown \& Arthur 2001). A participação do selênio na fisiologia do útero é vital, pois a função antioxidante é fundamental para manter o ambiente uterino o mais sadio possível, para a passagem dos espermatozoides, na época do cio, e para receber o embrião e protegêlo durante toda a gestação (Mirjana et al. 2016). Há evidência de que a concentração de glutationa reduzida no interior do oócito pode ser um bom sinal bioquímico para contribuir para o desenvolvimento da maturação nuclear e citoplasmático, em ruminantes (Mirjana et al. 2016). Huber et al. (2008) observaram em experimento realizado em camundongos, a enzima glutationa peroxidase extracelular, encontrada em líquidos adjacentes do embrião e metade da gestação, saco vitelínico, placenta e serve como proteção contra prejuízos de oxidação. O meio de cultura ágar gel (ITS - insulina - transferrina selênio) auxiliou na manutenção e no desenvolvimento de folículos pré-antrais caprinos, in vitro, por 14 dias (Huanmin \& Yong 2000). Houve redução da mortalidade embrionária durante a implantação, o que pode ter sido devido ao aumento do índice da fertilidade. Ainda, de acordo com o autor, este efeito pode ter ocorrido pelo aumento das contrações uterinas $\mathrm{e}$ as melhoras no transporte dos espermatozoides, efeitos que são, particularmente, importantes na superovulação.

Durante muitos anos o selênio foi mais considerado do ponto de vista de sua toxicidade de animais. No entanto, este elemento é considerado muito mais importante sob o aspecto de sua essencialidade, sendo necessário para o crescimento e fertilidade de animais. Em ovinos com deficiência em selênio verifica-se elevada mortalidade embrionária entre a $3^{\mathrm{a}}$ e $4^{\mathrm{a}}$ semana após a concepção, correspondendo ao tempo de implantação do embrião, é considerada como causa de infertilidade em ovinos na Nova Zelândia. No Brasil os trabalhos reportam os efeitos positivos da administração de selênio, associado ou não a vitamina $\mathrm{E}$, na diminuição de retenção de placenta (Mirjana et al. 2016).

De acordo com Behne et al. (1988) a secreção do hormônio testosterona é menor em animais que apresentam deficiência de selênio. De acordo com Hurley \& Doane (1989) o selênio pode estar associado à produção de prostaglandinas e que existe acúmulo de selênio nos placentomas, 
ovários, pituitária e glândula adrenal, sugerindo que haja exigências específicas nestes tecidos. Segundo Luberda (2005) a concentração de glutationa reduzida no interior do oócito pode ser um bom sinal bioquímico para contribuir para o desenvolvimento da maturação nuclear e citoplasmático, em mamíferos. Todavia, o entendimento da dinâmica da concentração de glutationa peroxidase durante a maturação do oócito e o desenvolvimento embrionário podem diminuir a infertilidade e aumentar a eficiência da produção de embriões (Luberda 2005). Portanto, o selênio pode reduzir a retenção de placenta e incrementar a performance reprodutiva visto que há indícios que a glutationa peroxidase protege a membrana dos oócitos contra danos oxidativos, o que coincide, em parte, com as observações de Luberda (2005).

De acordo com Eppig \& O'Brien (1996) e Krisher \& Bavister (1998) a glutationa peroxidase tem selênio revelado importante no processo de maturação de oócitos, envolvendo a síntese de componentes bioquímicos, fosforilação de proteínas e a ativação de caminhos metabólicos específicos. Entre os micros minerais, acredita-se que o selênio atue especificamente na melhora da sobrevivência do embrião (Gabryszuk \& Klewiec 2002).

Van Niekerk et al. (1996) reportaram que a suplementação de selênio 15 a 35 dias após o parto, via parenteral, reduziu a morte de embriões, em ovelhas, em 22 a $40 \%$. Um estudo realizado avaliando a suplementação de selênio referente à produção de embriões de cabras Saanen, constatou que a ingestão de $25 \mathrm{~g}$ de sal mineralizado contendo $30 \mathrm{mg}$ de se/kg de sal mineral é suficiente para produção de embriões com boa qualidade (Nascimento et al. 2008). Segundo Rock et al. (2001) a suplementação de ovelhas gestantes com selênio aumenta a e imunidade passiva para o feto. De acordo com El GhanyHefnawy et al. (2007) existe uma relação entre concentração de selênio fetal e materna em ovinos e caprinos durante todo o período gestacional.

\section{Se na sanidade de caprinos e ovinos}

Ao contrário de outros nutrientes, os minerais não podem ser sintetizados pelos seres vivos, deste modo devem ser adquiridos por de uma dieta que atenda as exigências de cada categoria e estado fisiológico a qual o animal está propenso. De maneira geral, as deficiências em balanços de minerais para ruminantes são relatadas em quase todas as regiões do mundo, sendo a perda e despigmentação de pêlos, doenças de pele, aborto não infeccioso, diarreia, anemia, perda de apetite, anormalidades ósseas, baixa fertilidade e depravação do apetite (comer ou lamber terra, casca de árvores, ossos, madeira etc) são os sintomas clínicos sugestivos de deficiências de minerais. Neste sentido, desde o ano de 1930 o selênio vem sendo pesquisado, na grande maioria das vezes relacionadas com problemas na sanidade. Entretanto, a busca de resultados no que tange o poder antioxidante para os animais, sobretudo aqueles de interesse zootécnico como os ruminantes é ânimo dos pesquisadores. Dentre distúrbios ocasionados pela a deficiência do selênio pode-se destacar a incidência de mastite retenção de placenta na fêmea, dentre outros (McDowell 2012). A utilização do selênio em vacas leiteiras possui inúmeros resultados na redução da incidência de mastite subclínica diagnosticada pelo California Mastitis Test (Paschoal et al. 2003). Outras funções do selênio seriam: 1) componente de uma proteína presente no músculo cardíaco; 2) componente de uma seleno-enzima presente no tecido muscular relacionada à atuação dos hormônios da tireoide; 3) componente de uma seleno-proteína específica dos espermatozoides; 4) tem função no RNA; 5) tem função específica na síntese de prostaglandinas e no metabolismo de ácidos graxos essenciais; 6) participa, junto com a vitamina $\mathrm{E}$ para que seja dada resposta adequada pelo sistema imune (proteção dos leucócitos e macrófagos durante o processo de fagocitose), havendo estudos que mostram benefícios de níveis superiores às exigências (McDowell 2012).

O selênio seria o mineral mais especificamente relacionado à função antioxidante. Há pelo menos 35 proteínas antioxidantes dentre essas pode-se incluir as seleno-proteínas $\mathrm{P}$, cinco $\mathrm{e}$ três glutationa peroxidases redutases tioredoxina, que agiria como uma segunda linha de defesa destruindo os peróxidos formados antes que sejam causado algum dano nas membranas celulares (Milad et al. 2001; Rooke et al. 2004).

Neste sentido, estudando o efeito do selênio nos tecidos e no sangue Qin et al. (2007) verificaram que as concentrações de selênio no rim, fígado e músculo aumentaram em todos os grupos suplementados quando comparado com o grupo controle. No entanto, as concentrações de selênio no rim, fígado e músculo nos grupos suplementados com levedura de selênio e selênio enriquecido probióticos foram maiores do que 
aqueles no grupo suplementado com selenito de sódio. As atividades da GSH-Px e as concentrações de selênio no sangue também aumentaram em todos os grupos suplementados durante $\mathrm{o}$ período de suplementação em comparação com o grupo controle. $\mathrm{O}$ que se pode perceber que as fontes selênio orgânico (levedura selenizada e se-enriquecido probióticos) são mais eficazes do que a fonte de selênio inorgânico (selenito de sódio) no tecido e aumentando as concentrações de selênio no sangue.

A suplementação com selênio e vitamina $\mathrm{E}$ intramuscular, na dose de $0,1 \mathrm{mg} \mathrm{kg}^{-1}$ e $2.000 \mathrm{UI}$ (duas aplicações com intervalo de 30 dias), respectivamente, não foi capaz de promover incremento proteico e imune quando cordeiros se encontravam severamente infectados pelo Haemonchus contortus. Em cordeiros sadios, a suplementação com selênio e vitamina E promoveu aumento nos teores de proteínas séricas e melhorou a resposta imune animal (Leal et al. $\underline{2010}$ ). Na mesma pesquisa os autores perceberam que a suplementação com selênio desde nascimentos aumenta o poder antioxidante contra o Haemonchus contortus. Também buscando avaliar efeitos do se no combate ao Haemonchus contortus em ovelhas, Camargo et al. (2010) analisaram o metabolismo oxidativo de neutrófilos no hemograma em ovinos infectados experimentalmente. Em ambos os animais, aqueles que não estimulados e os que foram estimulados, houve redução da atividade parasitária em 60 dias, a conclusão é que a suplementação com selênio proporciona melhor proteção antioxidante para os neutrófilos.

Em um estudo prospectivo de 1991 a 1998 Bickhardt et al. (1999) analisando as concentrações plasmáticas de vitamina $\mathrm{E}$ e Se o estudo foi aplicado em 125 ovelhas e 32 cabras com distúrbios motores generalizados, valores de Se $<0,08 \mathrm{mg} / \mathrm{l}$ foram considerados como deficiência. Os autores perceberam letalidade significativamente maior nos animais com deficiência combinada de vitamina $E$ e selênio (73\%) do que naqueles com deficiência de selênio (35\%). Já nos cordeiros a deficiência combinada de vitamina $\mathrm{E}+\mathrm{se}$ ocorreu (53\%), a qual muitas das vezes foi acompanhada com anemia (29\%) e hipoproteinemia (32\%).

A utilização da suplementação de se para animais gestantes é crucial principalmente no final da gestação e início de lactação, principalmente para evitar casos de mastite e retenção de placenta.
Somado a esse fator, quando se trata de ovelhas primíparas, a suplementação pode ter efeitos benéficos na transferência de imunidade passiva. Neste sentido, quando se utilizou se na nutrição de ovelhas primíparas sobre a morbidade de cordeiros, mortalidade e transferência passiva de imunoglobulinas $\mathrm{G}(\mathrm{IgG})$, os resultados dos estudos evidenciam que a suplementação com se pode aumentar a concentração sérica de $\operatorname{IgG}$ de cordeiros (Hammer et al. 2011). Adicionando o se na dieta de borregas, para a observação do desenvolvimento maternal e fetal, Taylor et al. (2009) observaram que a concentração de se nos tecidos maternos e fetais foram mais elevadas, provavelmente porque o Se oriundo da dieta que continha farelo de trigo enriquecida com $\mathrm{Se}$, atravessou a placenta mais eficientemente.

A preocupação com doenças no periparto e com as crias, é também motivo de pesquisas que envolvam o se, seguindo esse pensamento, Ramírez-Bribiesca et al. (2005) perceberam que a injeção de se em cabras deficientes aumenta os níveis séricos de se de $32 \%$, a conclusão que os pesquisadores chegaram é que a injeção com 0,3 $\mathrm{mg} \mathrm{se} / \mathrm{kg}$ de peso vivo aumentou a concentração de se no sangue em cabras gestantes e a dose foi efetiva para prevenir a doença de músculo branco e aumentar a sobrevivência dos cabritos até o desmame.

Com objetivo de determinar os efeitos da dieta materna de se supra-nutritional no plano nutricional durante a gestação sobre a densidade da superfície capilar, densidade de área capilar e expressão do fator angiogênico na glândula mamária no desenvolvimento de ovelhas primíparas, Vonnahme et al. (2011) observaram que borregas suplementadas com alta quantidade de se tinham maior superfície capilar e densidades de área em comparação com ovelhas de menores níveis de se, ademais os autores relatam que o plano nutricional materno não afetou a glândula mamária, concomitantemente o aumento da área capilar nas glândulas mamárias pode contribuir para alterações na qualidade do colostro.

A busca por resultados que melhorem a produção e qualidade do colostro sempre foram premissas para melhoria dos arranjos produtivos. No sentido de algumas modificações da dieta ocasionem bons resultados na qualidade do colostro, neste sentido, Meyer et al. (2011) objetivaram testar os efeitos da inclusão do Se na dieta de ovelhas primíparas no período da gestação sobre a composição do rendimento e de 
nutrientes do colostro e do leite. Os resultados indicaram que a nutrição gestacional afeta colostro e produção de leite e teor de nutrientes, mesmo quando as necessidades nutricionais sejam atendidas.

De uma maneira geral os resultados das pesquisas que envolvem o se pela enzima glutationa peroxidase junto com a vitamina $\mathrm{E}$, e os aminoácidos contendo enxofre previne a formação de hidroperóxidos de ácidos graxos e estão envolvidos no quebramento dos peróxidos, todos esses nutrientes levam a um resultado bioquímico similar, isto é, redução nos tecidos das concentrações de peróxidos ou de produtores induzidos por eles, ademais esse elemento pode potencializar as respostas imunes dos animais de produção, podendo assim repercutir em melhores resultados produtivos, igualmente a melhoria da qualidade da vida dos animais e produtos que eles produzem.

\section{Considerações Finais}

$\mathrm{O}$ se possui amplas funcionalidades nas áreas de nutrição, sanidade e reprodução, aprimorando os sistemas de produção de caprinos e ovinos, uma vez que aumenta o ganho de peso, a produção de leite e lã dos animais. Reduz o risco de doenças como a mastite e contaminações por verminose, além de aumentar a taxa de fertilidade, menores riscos de retenção de placenta. Todos esses pontos positivos relacionados com o uso do se levam aos pesquisadores buscarem cada vez mais pesquisas que aperfeiçoem o uso do mesmo, procurando concentrações adequadas para não causar toxicidade no animal e fornecer quantidades ótimas de se nos produtos dos animais. Consequentemente espera-se com o uso cada vez mais frequente deste mineral, possa proporcionar aos consumidores um alimento com o perfil nutricional cada vez melhor, podendo melhorar a alimentação dos mesmos e ajudar na prevenção de algumas doenças.

\section{Referências Bibliográficas}

Ashworth C.J. 1995. Maternal and conceptus factors affecting histotrophic nutrition and survival of embryos. Livestock Production Science 44, 99-105.

Behne D., Hilmert H., Scheid S., Gessner H. \& Elger W. 1988. Evidence for specific selenium target tissues and new biologically important selenoproteins. Biochimica et Biophysica Acta (BBA)-General Subjects 966, 12-21.
Berchielli T.T., Pires A.V. \& Oliveira S.G. 2011 Nutrição de Ruminantes. FUNEP, Jaboticabal, Brazil.

Bickhardt K., Ganter M., Sallmann P. \& Fuhrmann H. 1999. Investigations on manifestations of vitamin $\mathrm{E}$ and selenium deficiency in sheep and goats. Dtsch Tierarztl Wochenschr 106, 242-7.

Brown K.M. \& Arthur J.R. 2001. Selenium, selenoproteins and human health: a review. Public health nutrition 4, 593-9.

Bucak M.N., Ateşşahin A., Varışlı Ö., Yüce A., Tekin N. \& Akçay A. 2007. The influence of trehalose, taurine, cysteamine and hyaluronan on ram semen: microscopic and oxidative stress parameters after freeze-thawing process. Theriogenology 67, 1060-7.

Camargo E.V., Lopes S.T.A., Costa M.M., Paim F., Barbosa C.S. \& Leal M.L.R. 2010. Neutrophil oxidative metabolism and hemogram of sheep experimentally infected with Haemonchus contortus and supplemented with selenium and vitamin $\mathrm{E}$ or association. Journal of animal physiology and animal nutrition 94, 1-6.

Chauhan S.S., Celi P., Ponnampalam E.N., Leury B.J., Liu F. \& Dunshea F.R. 2014. Antioxidant dynamics in the live animal and implications for ruminant health and product (meat/milk) quality: role of vitamin E and selenium. Animal Production Science 54, 1525-36.

Costa R.G., Silva N.V., Medeiros G.R. \& Batista A.S.M. 2009. Características sensoriais da carne ovina: sabor e aroma. Revista Científica de Produção Animal 11.

Cristaldi L.A., McDowell L.R., Buergelt C.D., Davis P.A., Wilkinson N.S. \& Martin F.G. 2005. Tolerance of inorganic selenium in wether sheep. Small Ruminant Research 56, 205-13.

Davis P.A., McDowell L.R., Wilkinson N.S., Buergelt C.D., Alstyne R.V., Weldon R.N. \& Marshall T.T. 2006. Effects of selenium levels in ewe diets on selenium in milk and the plasma and tissue selenium concentrations of lambs. Small Ruminant Research 65, 14-23.

El Ghany-Hefnawy A., López-Arellano R., Revilla-Vázquez A., Ramírez-Bribiesca E. \& Tórtora-Pérez J. 2007. The relationship between fetal and maternal selenium concentrations in sheep and goats. Small Ruminant Research 73, 174-80. 
Eppig J.J. \& O'Brien M.J. 1996. Development in vitro of mouse oocytes from primordial follicles. Biology of reproduction 54, 197-207.

Filappi A., Prestes D. \& Cecim M. 2005 Suplementação mineral para bovinos de corte sob pastejo-revisão. Veterinária Notícias 11, 91-8.

Gabryszuk M. \& Klewiec J. 2002. Effect of injecting 2-and 3-year-old ewes with selenium and selenium-vitamin $\mathrm{E}$ on reproduction and rearing of lambs. Small Ruminant Research 43, 127-32.

Gresakova L., Cobanova K. \& Faix S. 2013. Selenium retention in lambs fed diets supplemented with selenium from inorganic or organic sources. Small Ruminant Research $111,76-82$.

Hall J.A., Van Saun R.J., Nichols T., Mosher W. \& Pirelli G. 2009. Comparison of selenium status in sheep after short-term exposure to high-selenium-fertilized forage or mineral supplement. Small Ruminant Research 82, 405.

Hammer C.J., Thorson J.F., Meyer A.M., Luther J.S., Neville T.L., Reed J.J., Reynolds L.P., Coton J.S. \& Vonnahme K.A. 2011. Effects of maternal selenium supply and plane of nutrition during gestation on passive transfer of immunity and health in neonatal lambs. Journal of animal science 89, 3690-8.

Huanmin Z. \& Yong Z. 2000. In vitro development of caprine ovarian preantral follicles. Theriogenology 54, 641-50.

Huber P.C., Almeida W.P. \& Fátima Â. 2008. Glutationa e enzimas relacionadas: papel biológico e importância em processos patológicos. Química Nova 31, 1170-9.

Hurley W.L. \& Doane R.M. 1989. Recent developments in the roles of vitamins and minerals in reproduction. Journal of Dairy Science 72, 784-804.

Juniper D.T., Phipps R.H., Ramos-Morales E. \& Bertin G. 2009. Effect of high dose selenium enriched yeast diets on the distribution of total selenium and selenium species within lamb tissues. Livestock science 122, 63-7.

Kamada H. \& Hodate K. 1998. Effect of dietary selenium supplementation on the plasma progesterone concentration in cows. Journal of Veterinary Medical Science 60, 133-5.

Khaled N.F. \& Illek J. 1999. Influence of dietary supplementation of selenium-enriched yeast on selenium status of dairy goats. In: Congress on Macro end Trace Elements, pp. 244-51.

Koenig K.M., Rode L.M., Cohen R.D.H. \& Buckley W.T. 1997. Effects of diet and chemical form of selenium on selenium metabolism in sheep. Journal of animal science 75, 817-27.

Krisher R.L. \& Bavister B.D. 1998. Responses of oocytes and embryos to the culture environment. Theriogenology 49, 103-14.

Lauzurica S., de la Fuente J., Díaz M.T., Álvarez I., Pérez C. \& Cañeque V. 2005. Effect of dietary supplementation of vitamin $\mathrm{E}$ on characteristics of lamb meat packed under modified atmosphere. Meat Science 70, 63946.

Leal M.L.R., Camargo E.V., Ross D.H., Molento M.B., Lopes S.T.A. \& Rocha J.B.T. 2010. Effect of selenium and vitamin $\mathrm{E}$ on oxidative stress in lambs experimentally infected with Haemonchus contortus. Veterinary Research Communication 34.

Luberda Z. 2005. The role of glutathione in mammalian gametes. Reproductive Biology 5, 5-17.

McDowell L.R. 2012. Vitamins in animal nutrition: comparative aspects to human nutrition. Academy Press, California.

McDowell R.E. \& Hernandez-Urdaneta A. 1975. Intensive systems for beef production in the tropics. Journal of animal science 41, 1228-37.

Mestchy F. 2000. Recent progress in the assessment of mineral requirement of goats. Livestock Production Science 64, 9-14.

Meyer A.M., Reed J.J., Neville T.L., Thorson J.F., Maddock-Carlin K.R., Taylor J.B., Reynolds L.P., Redmer D.A., Luther J.S., Hammer C.J., Vonnahme K.A. \& Caton J.S. 2011. Nutritional plane and selenium supply during gestation affect yield and nutrient composition of colostrum and milk in primiparous ewes. Journal of animal science 89, 1627-39.

Milad K., Racz O., Sipulova A., Bajová V. \& G. K. 2001. Effect of vitamin $E$ and selenium on blood glutathione peroxidase activity and some immunological parameters in sheep. Veterinarni Medicina 46.

Mirjana J.T., Davidović V. \& Mirjana B.R. 2016. The effects of some microelements supplementation-selenium, zinc and copper into dairy cows feeds on their health and 
reproductive performances. Biotechnology in Animal Husbandry 32, 101-10.

Mistry H.D., Pipkin F.B., Redman C.W.G. \& Poston L. 2012. Selenium in Reproductive Health. American Journal of Obstetrics \& Gynecology 206, 21-30.

Morgante M., Beghelli D., Pauselli M., Dall'Ara P., Capuccella M. \& Ranucci S. 1999. Effect of administration of vitamin $\mathrm{E}$ and selenium during the dry period on mammary health and milk cell counts in dairy ewes. Journal of Dairy Science 82, 623-31.

Munsi M.N., Bhuiyan M.M.U., Majumder S. \& Alam M.G.S. 2007. Effects of exogenous glutathione on the quality of chilled bull semen. Reproduction in domestic animals 42 , 358-62.

Nascimento E.E., Moraes G.V., Macedo F.A.F., Oliveira J.M., Azevedo J.R. \& Matovelli M. 2008. Suplementação de selênio na dieta de caprinos sobre a produção e qualidade do embrião. PUBVET 2, 1-11.

NRC 2001. Nutrient Requirements of Dairy Cattle. Natl. Acad. Press, Washington, DC., Washington.

Paschoal J.J., Zanetti M.A. \& Cunha J.A. 2003. Efeito da suplementação de selênio e vitamina E sobre a incidência de mastite clínica em vacas da raça Holandesa. Arquivos Brasileiros Medecina Veterinária Zootecnia 55, 249-55.

Pastrana R., McDowell L.R., Conrad J.H. \& Wilkinson N.S. 1991. Productivity of Colombian sheep supplemented with selenium. Small Ruminant Research 5, 217-22.

Petrera F., Calamari L. \& Bertin G. 2009. Effect of either sodium selenite or Se-yeast supplementation on selenium status and milk characteristics in dairy goats. Small Ruminant Research 82, 130-8.

Qin S., Gao J. \& Huang K. 2007. Effects of different selenium sources on tissue selenium concentrations, blood GSH-Px activities and plasma interleukin levels in finishing lambs. Biological Trace Element Research 116, 91102.

Ramírez-Bribiesca J.E., Tórtora J., Huerta M., Hernández L.M., López R. \& Crosby M.M. 2005. Effect of selenium-vitamin E injection in selenium-deficient dairy goats and kids on the Mexican plateau. Arquivo Brasileiro de Medicina Veterinária e Zootecnia 57, 77-84.
Rock M.J., Kincaid R.L. \& Carstens G.E. 2001. Effects of prenatal source and level of dietary selenium on passive immunity and thermometabolism of newborn lambs. Small Ruminant Research 40, 129-38.

Rooke J.A., Robinson J.J. \& Arthur J.R. 2004. Effects of vitamin $\mathrm{E}$ and selenium on the performance and immune status of ewes and lambs. Journal Agricutural Science 142, 25362.

Schrauzer G.N. \& Surai P.F. 2009. Selenium in human and animal nutrition: resolved and unresolved issues. A partly historical treatise in commemoration of the fiftieth anniversary of the discovery of the biological essentiality of selenium, dedicated to the memory of Klaus Schwarz (1914-1978) on the occasion of the thirtieth anniversary of his death. Critical Reviews in Biotechnology 29, 2-9.

Shi L., Xun W., Yue W., Zhang C., Ren Y., Shi L., Wang Q., Yang R. \& Lei F. 2011. Effect of sodium selenite, Se-yeast and nano-elemental selenium on growth performance, Se concentration and antioxidant status in growing male goats. Small Ruminant Research 96, 49-52.

Smith O.B. \& Akinbamijo O.O. 2000. Micronutrients and reproduction in farm animals. Animal reproduction science 60, 54960.

Soder K.J. \& Holden L.A. 1999. Dry matter intake and milk yield and composition of cows fed yeast prepartum and postpartum. Journal of Dairy Science 82, 605-10.

Souza A.R.M., Arthur V. \& Canniatti-Brazaca S.G. 2009. Influência da radiação gama e de diferentes dietas na qualidade da carne de cordeiros Santa Inês. Ciência e Tecnologia de Alimentos 29, 709-15.

Taylor J.B. 2005. Time-dependent influence of supranutritional organically bound selenium on selenium accumulation in growing wether lambs. Journal of animal science 83, 1186-93.

Taylor J.B., Reynolds L.P., Redmer D.A. \& Caton J.S. 2009. Maternal and fetal tissue selenium loads in nulliparous ewes fed supranutritional and excessive selenium during mid- to late pregnancy. Journal of animal science 87, 1828-34.

Van Niekerk D., Cloete F.E., Heine S.W.P., Van der Merwe E.W.P., Wellington G.D., Du Plessis A. \& Bekker S.S. 1996. The effect of selenium supplementation during the early 
pos-mating period on embryonic survival in sheep. Journal of the South African Veterinary Association 67, 209-13.

Van Soest P.J. 1994. Nutritional ecology of the ruminant. Cornell University Press, Ithaca, NY, USA.

Vignola G., Lambertini L., Mazzone G., Giammarco M., Tassinari M., Martelli G. \& Bertin G. 2009. Effects of selenium source and level of supplementation on the performance and meat quality of lambs. Meat Science 81, 678-85.

Vonnahme K.A., Wienhold C.M., Borowicz P.P., Neville T.L., Redmer D.A., Reynolds L.P. \&
Caton J.S. 2011. Supranutritional selenium increases mammary gland vascularity in postpartum ewe lambs. Journal of Dairy Science 94, 2850-8.

Article History:

Received 24 January 2018

Accepted 5 March 2018

Available online 15 May 2018

License information: This is an open-access article distributed under the terms of the Creative Commons Attribution License 4.0, which permits unrestricted

use, distribution, and reproduction in any medium, provided the original work is properly cited. 